\title{
Fibrochondrogenic potential of synoviocytes from osteoarthritic and normal joints cultured as tensioned bioscaffolds for meniscal tissue engineering in dogs
}

Meniscal tears are a common cause of stifle lameness in dogs. Use of autologous synoviocytes from the affected stifle is an attractive cell source for tissue engineering replacement fibrocartilage. However, the diseased state of these cells may impede in vitro fibrocartilage formation. Synoviocytes from 12 osteoarthritic ("oaTSB") and 6 normal joints ("nTSB") were cultured as tensioned bioscaffolds and compared for their ability to synthesize fibrocartilage sheets. Gene expression of collagens type I and II were higher and expression of interleukin-6 was lower in oaTSB versus nTSB. Compared with nTSB, oaTSB had more glycosaminoglycan and alpha smooth muscle staining and less collagen I and II staining on histologic analysis, whereas collagen and glycosaminoglycan quantities were similar. In conclusion, osteoarthritic joint-origin synoviocytes can produce extracellular matrix components of meniscal fibrocartilage at similar levels to normal joint-origin synoviocytes, which makes them a potential cell source for canine meniscal tissue engineering. 
1 Jennifer J. Warnock, DVM, PhD, DACVS, ${ }^{a}$ Gerd Bobe, MPH, PhD, ${ }^{b}$ Katja F.Duesterdieck-

2 Zellmer Dr.med.vet., MS, PhD, DACVS, ${ }^{a}$

3 a 105 Magruder Hall

$4700 \mathrm{SW} 30^{\text {th }}$ St.

5 Oregon State University

6 College of Veterinary Medicine

7 Corvallis, OR 97331

8 Phone: 541-737-6859

9 Fax: 541-737-4818

10 b 307 Linus Pauling Science Center

11 Linus Pauling Institute

12 Oregon State University

13 Corvallis, OR 97331

14 Phone: 541-737-1898

15 Fax: 541-737-4174

16 Address correspondence to Dr. Warnock (jennifer.warnock@oregonstate.edu). 


\section{1. Introduction:}

18 Meniscal injury is a common cause of lameness and pain of the dog. Due to the virtually

19 absent healing response in the majority of the meniscus, injured meniscal tissue is commonly

20 removed to relieve the clinical signs of lameness, joint locking, and painful popping.

21 Unfortunately, partial meniscectomy hastens the development of secondary arthritis (Berjon et

22 al., 1991; Connor et al., 2009; Cox et al., 1975) and thus patient lameness.

23 Tissue engineering methods are being investigated to address this challenge of meniscal

24 injury and loss. One of the great obstacles to achieving the reality of tissue engineered menisci is

25 determination of an ideal cell source for in vitro culture and extracellular matrix (ECM)

26 formation. Because cells cannot be synthesized de novo, they must be harvested autologously, or

27 obtained from living or deceased tissue donors. When determining ideal cell sources for tissue

28 engineering, location of the source tissue, quantity of donor tissue available for harvest, and

29 ability to harvest the cells in a minimally invasive fashion must be considered. Autologous cells

30 are particularly attractive because they have a low potential for infectious disease transmission

31 (Pessina et al., 2008) and immunogenic tissue rejection (Hamlet et al., 1997; Ochi et al., 1995;

32 Rodeo et al., 2000).

33 While producing normal, healthy menisci in vitro is the ultimate goal of tissue

34 engineering, use of normal meniscal cells from a healthy donor site would cause irreversible

35 patient harm and thus is a poor choice for meniscal tissue engineering. Mensenchymal stem cells

36 were recently identified in normal joint-origin canine synovium (Zhang et al., 2013), which could

37 be used towards in vitro meniscal fibrochondrogenesis. When cultured in monolayer, cells

38 obtained from the synovial membrane of normal joints are primarily positive for CD90 (marker

39 for stemness), CD29 ( $\beta$ - integrin), CD44 (hyaluronic acid receptor) and negative for markers of 
40 hematopoetic progenitors (CD34) and leukocyte antigens (CD45; Zhang et al.2013). These cells

41 are also able to undergo chondrogenesis when cultured in pellet form (Zhang et al.2013).

42 However, clinical use of normal autologous synoviocytes as a tissue engineering cell source

43 would require surgery on another unaltered joint within the patient's body.

44 Autologous, osteoarthritic joint-origin synovium has been investigated as a cell source for

45 fibrocartilage tissue engineering in dogs, because of its abundance and ease of harvest during 46 clinically required surgical procedures (Warnock et al., 2012). In vitro, cultured osteoarthritic

47 joint- origin canine synovial membrane cells are plastic adherant and fibroblast- like, and contain 48 populations of cells that can undergo chondrogenesis (Warnock et al., 2011, Warnock et al 2013), 49 suggesting the presence of mesenchymal stem cells. In vivo (Smith et al., 2012; Tienen et al., 50 2006) synovium also has the ability to form fibrocartilage ECM. Conversely, synoviocytes in 51 osteoarthritic joints secrete a number of inflammatory mediators and destructive matrix 52 metalloproteinases (Benito et al., 2005; Fiorito et al., 2005; Sutton et al., 2007), which could 53 inhibit in vitro fibrochondrogenic potential. For example, canine osteoarthritic joint-origin 54 synoviocytes produce less total collagen than normal joint-origin synoviocytes in monolayer 55 culture (Warnock et al., 2011). This limitation may not be present with improved culture 56 conditions (Warnock et al. 2013). For instance, osteoarthritic joint-origin synovial fluid stem cells 57 require culture as a micro-mass to undergo efficient in vitro chondrogenesis, compared to cells 58 derived from healthy joint fluid (Krawetz et al., 2012).

59 Thus, the purpose of this study was to evaluate and compare the fibrochondrogenic 60 potential of synoviocytes from osteoarthritic and normal canine joints that were cultured as 61 tensioned bioscaffolds under conditions previously shown to increase meniscal-like ECM content 62 in canine osteoarthritic joint-origin synoviocytes (Warnock et al., 2013). We hypothesized that 
63 with the use of this tensioned culture system, there would be no difference in cell viability and

64 fibrocartilage-like ECM formation between tensioned synoviocyte bioscaffolds from normal

65 joints (normal joint- origin tensioned synoviocyte bioscaffolds, "nTSB") and osteoarthritic joints

66 (osteoarthritic joint- origin tensioned synoviocyte bioscaffolds, “oaTSB”).

68 2. Materials and Methods

692.1 Tissue Harvest

70 With informed owner consent, synovium was obtained from 12 dogs with naturally

71 occurring clinical osteoarthritis as per Institutional Animal Care and Use Committee approval.

72 Dogs were treated for degeneration of the cranial cruciate ligament and medial meniscal injury

73 via exploratory arthroscopy, partial meniscectomy if indicated, and tibial plateau leveling

74 osteotomy. Synovial villi were arthroscopically harvested during routine partial synovectomy

75 using a tissue shaver (Stryker, San Jose, CA) as previously described (Warnock et al., 2012).

76 Synovial villi from the osteoarthritic joints were immediately placed in a $50 \mathrm{ml}$ polypropylene

77 tube containing 40mL of Dulbeccos' Modified Eagle's Media (DMEM, Invitrogen)) with 10\%

78 fetal bovine serum (FBS, Invitrogen), warmed to $37^{\circ} \mathrm{C}$. The tube was transported immediately to

79 the laboratory and centrifuged at $313 \mathrm{xg}$, media was decanted, and tissue fragments transferred by

80 pipette and sterile forceps into a digestion solution as described below.

81 Normal synovium was also harvested from six dogs which were euthanatized via sodium

82 pentobarbital overdose for reasons unrelated to the study, as per the Institutional Animal Care and

83 Use Committee Protocol and in accordance with the American Veterinary Medical Association

84 Humane Euthanasia Guidelines. Dogs were assessed by a Diplomate of the American College of

85 Veterinary Surgeons - Small Animal to not have any orthopedic disease based on medical history, 
86 pre-mortem physical examination, and post- mortem gross joint evaluation. Post- mortem, a

87 lateral arthrotomy and patellar tendon transection was performed on each stifle joint. The

88 parapatellar, suprapatellar, lateral, and medial wall synovium were dissected off the joint capsule

89 using a \#15 bard parker blade. Synovium was transported as described above. In the laboratory,

90 synovium harvested from normal joints was additionally was minced into $2 \times 3 \mathrm{~mm}$ pieces using

91 sterile technique.

\section{2.2 Cell Culture}

93 Osteoarthritic joint- origin synovial villi and normal joint- origin synovium tissue

94 fragments were completely digested with sterile Type $1 \mathrm{~A}$ clostridial collagenase $10 \mathrm{mg} / \mathrm{mL}$ in

95 RPMI 1640 solution (Invitrogen) over 2-6 hours at $37^{\circ} \mathrm{C}$. Tissue was deemed to be completely

96 digested when no ECM could be visualized microscopically at 20x objective magnification. Cells

97 were cultured in monolayer for four passages to isolate Type B fibroblast-like synoviocytes

98 (Vasanjee et al., 2008) and Type C intermediate synoviocytes (Vasanjee et al., 2008) as described

99 previously (Warnock et al., 2012). The following media formulation was used for the duration of

100 culture: high glucose DMEM, supplemented with $17.7 \%$ FBS, $0.021 \mathrm{mg} / \mathrm{mL}$ glycine,

$1010.025 \mathrm{mg} / \mathrm{mL}$ L-alanine, $0.037 \mathrm{mg} / \mathrm{mL}$ L- asparagine, $0.038 \mathrm{mg} / \mathrm{mL}$ L-aspartic acid, $0.042 \mathrm{mg} / \mathrm{mL}$

102 L-glutamic acid, $0.033 \mathrm{mg} / \mathrm{mL}$ L-proline, $0.030 \mathrm{mg} / \mathrm{mL}$ L-serine, $0.23 \mathrm{mg} / \mathrm{mL}$ pyruvate,

$1030.52 \mathrm{mg} / \mathrm{mL}$ L-glutamine, $6.75 \mathrm{mg} / \mathrm{mL}$ HEPES buffer, 177.0 units $/ \mathrm{mL}$ penicillin, $177.0 \mu \mathrm{g} / \mathrm{mL}$

104 streptomycin, and $0.44 \mathrm{ug} / \mathrm{mL}$ amphoterocin). The flasks were incubated at $37^{\circ} \mathrm{C}, 5 \% \mathrm{CO}_{2}, 95 \%$

105 humidity, with sterile media change performed every 24 hours.

106 Cell flasks were observed under 10x objective magnification every 24 hours to assess

107 confluency. Cells were passaged upon reaching 95\% confluence, which was defined as

108 monolayer cell culture with no visible exposed flask surface in between cells, and no overlap of

109 the cells on each other. At harvest and at each passage cell viability counts were performed using 
110 the trypan blue exclusion assay (Strober, 2001). At the 4th passage, cells from each joint were

111 transferred into eight $150 \mathrm{~cm}^{2}$ flasks and allowed to become hyperconfluent cell sheets, defined as

112 cells overlapping each other in greater than $100 \%$ confluency. TSB were then made as previously

113 described (Warnock et al., 2013). Briefly, hyperconfluent cell sheets were dislodged off the flask

114 floors (Ando et al., 2008), and each sheet was wrapped over $2.0 \mathrm{~cm}$ diameter, 22ga cerclage wire

115 hoops in three layers, with approximately $0.5 \mathrm{~N}$ of tension to avoid tearing, to synthesize TSB.

116 The TSB were placed in 6-well plates in $9.0 \mathrm{~mL}$ of the above described culture media, with the

117 free end of the cell sheet facing down to prevent loosening. Bioscaffolds were harvested for

118 analysis after a total of 30 days in culture (Ando et al., 2008; Tan et al., 2010).

\subsection{Bioscaffold Analyses}

120 Bioscaffolds analyses examined presence of ECM components responsible for meniscal

121 form and function. These include type I collagen, which, in the bovine, constitutes up to $98 \%$ of

122 meniscal collagen, (Eyre and $\mathrm{Wu}, 1983$ ) and subjectively, in the dog, accounts for the

123 preponderance of meniscal collagen (Kambic and McDevitt, 2005); type II collagen, which

124 accounts for a very small proportion of meniscal collagen (Eyre and $\mathrm{Wu}, 1983$ ); $\alpha$ - smooth

125 muscle actin (ASM) (Ahluwalia et al., 2001; Kambic et al., 2000; Spector, 2001); and

126 glycosaminoglycans (GAG) (Adams and Ho, 1987; Nakano et al., 1997; Stephan et al., 1998),

127 including aggrecan (Valiyaveettil et al., 2005). Differences in expression of inflammatory

128 mediators or presence of macrophages were investigated as these factors may be associated with

129 decreased in vitro ECM synthesis in osteoarthritic joint-origin synoviocytes (Fiorito et al., 2005;

130 Pei et al., 2008a).

131 Cell Viability: One TSB per dog was washed three times in sterile phosphate buffered

132 saline and immersed in $4 \mu \mathrm{M}$ ethidium homodimer and $6 \mu \mathrm{M}$ acetomethoxy calcein (calcein - AM) 
133 solution (Ethidium homodimer and Calcein AM Live/Dead Viability Assay, Invitrogen, Carlsbad,

$134 \mathrm{CA}$ ) for 20 minutes at $37^{\circ} \mathrm{C}, 5 \% \mathrm{CO} 2,95 \%$ humidity. Cells were then visualized in at least five

135 regions of the bioscaffolds, (and two in the center and three on the periphery, at approximately

136 the 2, 6, and 10 o'clock positions) using a laser microscope (Eclipse Ti-u Laser Microscope,

137 Nikkon, Japan). The number of viable (green) and non- viable (red) cells per each field counted

138 by hand. Due to the complex three -dimensional nature of the bioscaffolds, these cell counts

139 provided an estimate of cell viability.

140 Immunohistologic Analysis: Two TSB per dog were fixed in 10\% buffered formalin,

141 paraffin embedded, and tissue blocks cut in $4 \mu \mathrm{m}$ sections for histologic and immunohistologic

142 analysis. All slides were labelled with randomly generated acquisition numbers and analyzed in a

143 blinded fashion. Sections were stained with Hematoxylin and Eosin ("H\&E”), Masson's

144 Trichrome, and Toluidine Blue. Cell morphology and general ECM architecture was assessed

145 using H\&E; organization and intensity of collagen staining was described using Masson's

146 Trichrome, and intensity of GAG staining was assessed using Toluidine Blue.

147 Immunohistochemistry: Immunohistochemistry was performed as previously described

148 (Warnock et al., 2012) for type I collagen (AB749P; 1:100 dilution; Millipore), type II collagen

149 (AB746P; 1:100: Millipore), macrophage MAC387 receptor to determine type A synoviocyte

150 content, (CBL260; 1:200 dilution; Millipore); and alpha smooth muscle actin (M0851; 1:30;

151 Dako). Extracellular and intracellular immunoreactivity intensity and prevalence was scored as

152 previously described (Wakshlag et al. 2011) with some modifications: immunoreactivity was

153 localized to intracellular or extracellular staining, and ECM immunoreactivity intensity was

154 described and scored, as negative (0), mild (1), moderate (2), or strong (3) staining. As

155 determined by hand count, intracellular immunoreactivity and extracellular immunoreactivity 
156 was categorized as positive in $<10 \%, 10-50 \%$, or $>50 \%$ of cells and sample area, respectively.

157 Each of these histologic observations was assigned a score (Table 2). Then a histologic intensity

158 coefficient was calculated for each ECM component, as follows: [[(Extracellular matrix staining

159 intensity score) $\mathrm{x}$ (percentage area coverage of positive staining score) $]+[($ Intracellular staining

160 intensity score) $\mathrm{x}$ (percentage positive staining cells score)]]/2 (Table 1).

161 Tissue Weight: One TSB per dog was lyophilized and a dry weight obtained. Samples were 162 digested in 1.0ml Papain Solution (2mM Dithiothreitol and 300ug/ml Papain) at $60^{\circ} \mathrm{C}$ in a water 163 bath for 24 hours. This papain digest solution was used to obtain double stranded DNA (dsDNA), 164 GAG and collagen content of the bioscaffolds.

DNA Quantification: Double stranded DNA quantification assay (The Quant-iT

166 PicoGreenTM Assay, Invitrogen) was performed per manufacturer's instructions; double stranded 167 DNA extracted from bovine thymus was used to create standards of 1,000, 100, 10, and $1 \mathrm{ng} / \mathrm{mL}$.

168 Standard and sample fluorescence was read by a fluoromoter (Qubit, Invitrogen) at 485nm 169 excitation/ 528nm emission, and dsDNA concentration was determined based on the standard 170 curve.

171 Biochemical ECM Analysis: Glycosaminoglycan content was determined by the di-methyl-

172 methylene blue sulfated glycosaminoglycan assay (Farndale et al., 1986) using a

173 spectrophotometer (Synergy HT- KC4 Spectrophotometric Plate Reader and FT4software,

174 BioTec, Winooski, VT). Collagen content was determined by Erlich's hydroxyproline assay, as

175 described by Reddy et al. (Reddy and Enwemeka, 1996). Hydroxyproline content was converted

176 to collagen content using the equation: $\mu \mathrm{g}$ hydroxyproline $\mathrm{x}$ dilution factor $/ 0.13=\mu \mathrm{g}$ collagen

177 (Ignat'eva et al. 2007), because hydroxyproline consists of approximately 13\% of the amino 
178 acids in human meniscal collagen (Fithian, et al., 1990). Collagen and GAG content were

179 standardized to tissue dry weight as percentage of dry weight, to compare the experimental

180 neotissues to previously reported normal meniscal ECM content (Eyre and Wu, 1983). Total

181 GAG and collagen content were also reported in $\mu \mathrm{g} /$ neotissue to measure total synthetic activity

182 over the course of 30 days in each TSB. GAG and collagen content were additionally

183 standardized to dsDNA content using the following equations: [ $\mu$ g GAG/ ug dsDNA](Li and Pei,

1842011 ) and [ $\mu$ g collagen/ ug dsDNA] to identify chondrogenic cellular activity of each tested cell 185 origin.

Real-Time RT-PCR: One TSB per dog was snap frozen in liquid nitrogen and stored at -80

$187{ }^{\circ} \mathrm{C}$. Total RNA was isolated using the phenol-chloroform extraction (Chomczynski P, 1986) with

188 slight modifications. Samples were pulverized using a liquid nitrogen-cooled custom-made

189 stainless steel pulverizer and homogenized in trizol (Trizol, Qiagen Sciences, $0.025 \mathrm{~mL} / \mathrm{mg}$ of

190 tissue) and mixed with chloroform. The aqueous phase was then treated with isopropanol to

191 precipitate nucleic acids. RNA of samples was purified using on-column DNAse digestion

192 (RNeasy, Qiagen Sciences).

193 The RNA quality and quantity was determined using capillary electrophoresis (RNA 6000

194 Nano LabChip Kit, Agilent 2100 Bioanalyzer, Agilent Technologies), and RNA integrity numbers

195 (Imbeaud S, 2005) were determined (2100 Expert software, Agilent Technologies).

196 First-strand cDNA synthesis was performed from 400 ng total RNA(SuperScript III First-

197 Strand Synthesis System, Invitrogen Life Technologies, Carlsbad, CA) and Oligo-(dT)20 primers.

198 To control for possible genetic DNA contamination, non reverse-transcribed samples were also 199 processed. 
201 Foster City, CA) were obtained for each of the genes of interest: IL-1 $\beta$, IL-6, TNF- $\alpha$, SOX-9 (an

202 embryonic chondrogenic transcription factor), collagen type I $\alpha$ 1, collagen type II $\alpha$ 1, aggrecan,

203 and the reference gene GAPDH (see Appendix 1). All assays were confirmed to amplify their

204 targets at 95\% or greater efficiency using RNA from tissues of interest. Quantitative real-time

205 PCR was performed (StepOnePlus RT-PCR System, Applied Biosystems Inc.) using a proprietary 206 reagent system (TaqMan Gene Expression Master Mix, Applied Biosystems Inc.) Controls

207 included template-free negative controls and non reverse-transcribed negative controls. All

208 samples were run in triplicates and all negative controls were run in duplicates for 40 cycles (15

209 seconds at $95^{\circ} \mathrm{C}, 1$ minute at $60^{\circ} \mathrm{C}$ ) after 2 minutes of incubation with Uracil-DNA Glycosylase

210 at $50^{\circ} \mathrm{C}$, and 10 minutes at $95^{\circ} \mathrm{C}$ of enzyme activation.

211 Quantitative gene expression was determined in triplicates using the comparative CT

212 method (Schmittgen TD, 2008). The gene GAPDH was used as internal control (housekeeping

213 gene). Threshold cycles (CT) for each gene were defined by recording the cycle number at which

214 fluorescence reached a gene-specific threshold. Fold changes for gene expression data were

215 calculated using the following formula: fold change $=2^{-\Delta \Delta C \mathrm{CT}}=\left[\left(\mathrm{C}_{\mathrm{T}} \mathrm{gene}\right.\right.$ of interest -

$216 \mathrm{C}_{\mathrm{T}}$ housekeeping gene GAPDH $\left.)_{\mathrm{nTSB}}-\left(\mathrm{C}_{\mathrm{T}} \text { gene of interest }-\mathrm{C}_{\mathrm{T}} \text { housekeeping gene GAPDH }\right)_{\mathrm{o} \text { TSB }}\right]$.

\section{2.4 Statistical Methods}

218 A D'Agostino \& Pearson omnibus normality test was performed on all data to test for

219 normality. Cell harvest data was non- parametric data and was analyzed with a Wilcoxon

220 matched-pairs signed rank test, and data reported as median and interquartile range. Significance 
221 was declared at $\mathrm{P}<0.05$. Data were analyzed with a statistical software program Graph Pad 222 Prism, San Diego, CA.

223 The effect of osteoarthritis (osteoarthritic versus normal joint status) on gene expression

224 and ECM composition was analyzed using a 2-tailed Student's $t$-test, assuming unequal

225 variances. The effect of osteoarthritis on the histologic scoring of TSB extracellular matrix

226 formation was analyzed using a non-parametric Mann-Whitney U-test; ranking of the histologic

227 scores was performed using a Kruskal-wallis analysis on ranks followed by a Fisher's exact test.

228 Significance was declared at $\mathrm{P}<0.05$. Data were analyzed using Statistical Analysis System, 229 version 9.3 (SAS Institute Inc., Cary, NC).

230

231 3. Results

\section{3.1 Cell Harvest:}

233 The mean age of dogs with stifle osteoarthritis was 4.7 years (range: $2-8$ years). Breeds

234 represented included: Golden Retriever (1), American Staffordshire Terrier (2), Labrador

235 Retriever (3), Australian Shepherd (1), Rottweiler (2), Boston Bull Terrier (1), Goldendoodle (1),

236 and mixed breed (1), with 7 neutered males, 4 spayed females, and one intact female dog. As

237 observed by a Diplomate of the American College of Veterinary Surgeons - Small Animal, all

238 dogs had marked villous synovial hyperplasia and osteophytosis, and grade 1-2 Outerbridge

239 cartilage lesions of the medial femoral condyle and tibial plateau (Outerbridge, 1961). Cell yield

240 from arthroscopic synovial debris was $1.9 \times 10^{6} \pm 3.7 \times 10^{5}$ cells per joint, and cells were $99.5 \%$

$241 \pm 0.002$ viable at harvest. 
243 included: Red Tick Hounds (4), Labrador Retriever (1), and American Staffordshire cross (1),

244 with 3 female intact dogs, 2 male intact dogs, and one neutered male. Cell yield per joint was 1.4

$245 \times 10^{7} \pm 2.6 \times 10^{6}$ per joint and cells were $99.5 \% \pm 0.01$ viable. As the entire stifle joint synovial

246 membrane could be harvested post mortem, a greater volume of tissue and thus greater cell

247 numbers were obtained from the normal joints versus arthroscopic harvest of the osteoarthritic

248 joints $(P=0.01)$.

\subsection{Cell Culture and Cell Characterization:}

250 At $4^{\text {th }}$ passage, cells were transferred into eight $150 \mathrm{~cm}^{2}$ flasks in order to have enough

251 TSB for tissue analyses. This, however, resulted in greater cell seeding numbers for nTSB versus

252 oa TSB. Thus, normal joint-origin synoviocytes were seeded at $1.49 \times 10^{7}$ cells per flask,

253 wherease $6.52 \times 10^{6}$ osteoarthritic joint-origin cells were seeded per flask. At $4^{\text {th }}$ passage, normal

254 joint-origin cells were $99.0 \pm 0.4 \%$ viable compared with $98.8 \pm 0.4 \%$ viability of osteoarthritic

255 joint-origin cells $(P=0.85)$. Culture duration from tissue harvest to hyperconfluent cell membrane

256 formation and synthesis of TSB was 37.6 days and similar for both cell origins (range 20-49

257 days).

258

259 During the first week of tensioned bioscaffold culture, the culture media phenol red $\mathrm{pH}$

260 indicator changed to yellow by the time the 24 hour media change was required, indicating

261 marked increase in media acidity. In addition, during the first 7-10 days of culture, approximately

262 2-3 bioscaffolds per normal and osteoarthritic joint unraveled or slipped off their wire hoops (no

263 group differences observed), and were not analyzed in this study. The typical appearance of intact

$264 \mathrm{nTSB}$ and oaTSB is pictured in Fig. 2; thickness of TSB was 2-3mm. 
$26627.5-50.4 \mathrm{mg}$ ), which was more than for oaTSB (23.6mg, range 10.2-50.1 $\mathrm{mg} ; P=0.008$ ).

268 (range: 72-86\%). Cell viability was not associated with peripheral versus central location on the

269 TSB. Laser microscopy revealed cells with fusiform, fibroblastic cytoplasm, oriented parallel

270 with the vector of tension, as well as the presence of acellular, circular regions in the bioscaffolds.

271 Hematoxylin and eosin staining revealed highly cellular bisocaffolds, with layers of fibroblastic

272 cells organized in parallel, as sheets or bands, or variably arranged in whorls, with eosinophilic

273 ECM (Fig.3). Subjectively, both nTSB and oaTSB had heterogeneous extracellular matrix

274 architecture and cell distribution, with regions of dense cellularity and regions of dense

275 extracellular matrix (Fig. 3).

276 Percent dsDNA content was used to quantify tissue cellularity. Despite an initial higher

277 seeding cell count at $4^{\text {th }}$ passage, dsDNA accounted for $0.11 \pm .02 \%$ of nTSB dry weight, versus

$2780.21 \pm 0.03 \%$ of oaTSB dry weight $(P=0.01)$

279 Immunohistologically, oaTSB had more ASM positive cells than nTSB; the median

280 histologic score for nTSB was 6 versus 9 for oaTSB $(p=0.0102$, Fig.4). Nine of 12 oaTSB had

281 the highest possible ASM histologic scores of 9, whereas none of the nTSB achieved a perfect

282 score of $9(\mathrm{P}=0.009$, Fig.4). In $50 \%$ of all bioscaffolds, ASM positive cells were concentrated

283 around the bisocaffold periphery and around the margins of what appeared to be spontaneously

284 forming circular defects ranging from 70-600 $\mu \mathrm{m}$ (Fig.3). These circular defects corresponded

285 with the acellular regions viewed on laser microscopy. The other $50 \%$ of bioscaffolds did not

286 contain circular defects, nor did ASM expression seem to be geographically localizable. 
288 increase; $P=0.04)$ and type II collagen ( 71 -fold increase; $P=0.02)$ and a lower gene expression

289 of interleukin-6 (19-fold decrease; $P=0.001)$ versus nTSB. No significant changes were

290 observed for relative expression of SOX-9 $(P=0.72)$, aggrecan $(P=0.84)$, and tumor necrosis

291 factor- $\alpha(P=0.77$; Table 2$)$. Interleukin- $1 \beta$ was not expressed at detectable levels in any

292 bisocaffolds.

294 content of nTSB ( $\mathrm{P}=0.02$; Table 3$)$. After adjustment for dry weight or DNA content, no

295 significant group differences were observed.

Glycosaminoglycan was deposited regionally in all bioscaffolds but more GAG staining was observed in oaTSB than in nTSB. Median GAG histologic score was 1.0 for nTSB and 3.0 298 for oaTSB ( $\mathrm{P}=0.0007$, Figs. 4,5). Only 1 of $6 \mathrm{nTSB}$ had a GAG histologic score above 1 , whereas 29911 of 12 oaTSB had GAG histologic score above $1(\mathrm{P}=0.004$, Fig.4). 
307 However, 4 of 6 nTSB had a type I collagen histologic score greater than 7.5, versus only 1 of 12 308 oaTSB had a collagen score of 7.5 (P=0.02, Fig.4). Histologically, nTSB had more type II

309 collagen than oaTSB (Fig.6); median type II collagen histologic scores were 4.0 in nTSB and 2.5

310 in oaTSB, $(\mathrm{P}=0.03$, Fig. 4$)$. None of the oaTSB had a score greater than 2.5 whereas 5 of 6 nTSB

311 had a collagen type II histology score of $2.75(\mathrm{P}=0.0007$, Fig 4).

312 Synovial Macrophage Content: Based on immunohistochemistry, no macrophages 313 (Type A synoviocytes) were found in any bisocaffolds (Fig.7).

314 4.0 Discussion

315 Previous studies comparing in vitro canine synoviocyte fibrochondrogenesis in monolayer

316 culture (Warnock et al., 2011), and canine synoviocyte chondrogenesis in micromass culture

317 (Krawetz et al., 2012) concluded that osteoarthritic synoviocytes had inferior in vitro

318 fibrochondrogenic potential, compared with normal synoviocytes. Fiorito and workers came to a

319 similar conclusion in a study comparing in vitro chondrogenesis of human synoviocytes grown in

320 pellet culture, as determined by histologic analysis (Fiorito et al., 2005). In contrast, with the

321 culture conditions in the present study, especially providing conditions for self-tensioning, cells

322 originating from osteoarthritic joints increased type I and II collagen gene expression, and oaTSB

323 contained similar total collagen content, as compared to nTSB. While tissue dry weight and thus

324 total GAG content of oaTSB was lower than nTSB, a significant difference in GAG content

325 standardized to dry weight and cellularity could not be detected between oaTSB and nTSB.

326 Histologic analysis using toluidine blue, a semi-quantitative measure of GAG, revealed more

327 GAG deposition in oaTSB than nTSB. Thus, the greater dry weight of nTSB versus oaTSB was

328 likely due to unmeasured ECM components such as fibronectin, type III and VI collagen, and

329 vitronectin (Ando et al., 2007; Ando et al., 2008), which are found in native synovium (Okada et 
330 al., 1990; Price et al., 1996). These findings also indicate that given the chance to self- tension,

331 autologous, diseased synoviocytes can produce the ECM components of fibrocartilage in vitro at

332 a comparable level of normal joint-origin synoviocytes.

333 The unstable mechanical environment and inflammatory environment of the cranial

334 cruciate ligament deficient joint favors synovial intimal hyperplasia and synovial membrane and

335 joint capsule fibrosis (Bleedorn et al., 2011; Buckwalter, 2000; Oehler et al., 2002; Smith et al.,

336 1997), all of which were encountered in the osteoarthritic joints in the present study. The in vivo

337 pathogenic synovial hyperplasia may have accounted for the collagen gene upregulation seen in

338 oaTSB. Rat and human osteoarthritic synoviocytes spontaneously express TGF $\beta-1$ and its

339 receptor (Fiorito et al., 2005; Mussener et al., 1997), which is a pro-collagen and chondrogenic

340 growth factor (Daireaux et al., 1990; Leask and Abraham, 2004; Miyamoto et al., 2007; Pangborn

341 and Athanasiou, 2005a, b; Pei et al., 2008b). Upregulation of TGF $\beta$-1 and its receptor may also

342 be a plausible mechanism for oaTSB collagen gene upregulation. Collagen II upregulation

343 seemed to occur independently of SOX-9 expression, a finding duplicated in cultured human

344 osteoarthritic chondrocytes (Aigner et al., 2003). Additionally, decreased expression of IL-6 gene

345 may be a mechanism for the observed upregulation of type II collagen genes in oaTSB; IL-6 has

346 been found to inhibit chondrogenic differentiation of murine marrow mesenchymal cells (Wei et

347 al., 2013). Further research is required to confirm the mechanism of hyaline chondrogenic ECM

348 formation in canine TSB, through immunohistochemistry of TGFbeta-receptor and SMAD-

349 family protein expression (Xu et al., 2012).

Despite equal quantities of non-specific collagen in nTSB and oaTSB, immunohistologic

351 analysis revealed less type I and type II collagen in oaTSB, particularly in the ECM. Post

352 translation regulation by prolyl-4-hydroxylases (Grimmer et al., 2006) or ECM degradation by 
353 synovial matrix metalloproteinases (Fiorito et al., 2005) may have decreased oaTSB

354 accumulation of type I and II collagen accumulation, despite increased collagen gene expression.

355 IL-6 has also been found to increase gingival fibroblast synthesis of type I collagen in vitro

356 (Martelli-Junior et al., 2003), and increase type I collagen synthesis by tenocytes in vivo

357 (Andersen et al., 2011). It is possible that the decreased IL-6 gene expression in oaTSB

358 synoviocytes also decreased type I collagen formation as seen on histologic analysis. One

359 weakness of our study was that expression of type I and II collagen was not corroborated with a

360 Western blot, nor quantified via ELISA, to further our understanding of this discrepancy between

361 histologic collagen expression and collagen gene expression. Additionally we did not characterize

362 the percentage and type of mesenchymal progenitor cells present in normal versus osteoarthritic

363 synovium; difference in number and chondrogenic potential of these cells may have also

364 accounted for a difference in collagen ECM formation.

Other osteoarthritic cell types, such as chondrocytes, have reduced cell proliferation

366 compared to normal cells in monolayer culture (Acosta et al., 2006). In contrast, oaTSB

367 contained more dsDNA per dry weight than nTSB, despite the lower harvest cell yield and lower

368 cell seeding density at $4^{\text {th }}$ passage of osteoarthritic joint- origin synoviocytes. There was an

369 intrinsic weakness of our study; by clinical necessity, synovium from osteoarthritic joints was

370 harvested using a different technique (arthroscopy) than the normal joints (arthrotomy), and more

371 synoviocytes can be obtained via arthrotomy. Although cell growth kinetics was not the focus of

372 this study, cell culture media containing 17.7\% FBS likely provided mitotic stimuli to support

373 and increase oaTSB cellular proliferation. The markedly hyperplastic state of the synovium in

374 vivo may also have primed the osteoarthritic cells to continue to proliferate in vitro. Cell viability

375 was high at harvest and at the start of $4^{\text {th }}$ passage, but declined in all TSB; due to the long culture

376 period, cell mortality may have been caused by senescence. Additionally, as evidenced by media 
377 color changes, inadequate nutrient delivery to TSB in the culture wells and daily shifts in pH may

378 have also led to nTSB and oaTSB cell mortality. This cell mortality may have affected ECM

379 formation in both groups: the collagen content of nTSB (12\%) and oaTSB (16\%) did not reach

380 that of the healthy meniscus, at $60-70 \%$ of dry weight (McDevitt and Webber, 1990), although the

381 GAG content of nTSB (1.7\%) and oaTSB (2\%) did approximate the 2-3\% GAG per dry weight

382 of the whole meniscus (McDevitt and Webber, 1990; Stephan et al., 1998).

383 Consistent with prior studies (Warnock et al. 2013), all oaTSB and nTSB in the present

384 study were negative for any macrophages, which have been reported to contaminate human

385 osteoarthritic synoviocyte monolayer cultures and reduce in vitro chondrogenic activity (Pei et

386 al., 2008a) by contributing to the inflammatory milieu. In the present study, 4 passages and long

387 term culture as TSB likely eliminated any non-adherent cells, including synovial macrophages

388 (Krey et al., 1976). Synovium from osteoarthritic joints has also been found to express

389 inflammatory cytokines (Fiorito et al., 2005). Both nTSB and oaTSB expressed similar RNA

390 quantity of the TNF $\alpha$ gene, indicating an inflammatory response in in vitro culture (Lindroos et

391 al., 2010), independent of the diseased status of the cell origin. Paradoxically, IL-6 expression

392 was decreased in oaTSB. Although the exact reason for this is unclear, decreased IL-6 gene

393 expression may represent the response of synoviocytes from osteoarthritic joints to the change in

394 environment; from the high motion, inflamed stifle containing multiple injured cell types

395 (ligament, cartilage, meniscus, synovium) to the static tension of TSB culture and high FBS

396 concentration cell culture media.

397 Decreased IL-6 in oaTSB may have reflected better mechanical homeostasis (Asparuhova

398 et al., 2009; Chan et al., 2011; Gardner et al., 2012) in the cells in oaTSB: the majority of cells in

399 oaTSB were uniformly positive for ASM, while 10-50\% of nTSB cells were ASM positive.

400 Synoviocytes increase expression of intracellular ASM in response to TGF $\beta-1$ (Xu et al., 2012). 
401 Endogenous receptivity in osteoarthritic origin-joint synoviocytes to TGF $\beta$-1 present in FBS

402 (Goddard et al., 1990; Mussener et al., 1997) may explain increased ASM in the cells of oaTSB.

403 In the present study, staining for ASM was positively associated with the formation of circular

404 defects, indicating that the ECM was not strong enough to prevent tears from forming during

405 ASM-mediated self-tensioning (Kambic et al., 2000; Vickers et al., 2004; Warnock et al., 2013).

406 Given the higher dsDNA content of oaTSB and the high cellularity of the TSB, these defects may

407 have also been caused by increased cell turnover.

Conclusion: When cultured as TSB in high concentrations of FBS, osteoarthritic joint-

409 origin synoviocytes can produce ECM components of meniscal fibrocartilage at similar levels to

410 normal joint- origin synoviocytes. Potential reasons for this include increased collagen and

411 decreased IL-6 gene expression and the greater GAG and ASM staining in oaTSB compared with

412 nTSB Osteoarthritic joint-origin synoviocytes are a viable cell source toward meniscal tissue

413 engineering. Further investigation of culture environments to optimize cell viability and ECM

414 formation and strength are justified due to the promising data reported here.

415 Acknowledgements: the authors give a profound thanks to Jesse Ott, for technical

416 assistance with performing the assays used in this study. 
417 References

418 Acosta, C.A., Izal, I., Ripalda, P., Douglas-Price, A.L., Forriol, F., 2006. Gene expression and

419 proliferation analysis in young, aged, and osteoarthritic sheep chondrocytes effect of growth

420 factor treatment. Journal of Orthopedic Research 24, 2087-2094.

421 Aigner, T., Gebhard, P.M., Schmid, E., Bau, B., Harley, V., Poschl, E., 2003. SOX9 expression

422 does not correlate with type II collagen expression in adult articular chondrocytes. Matrix

423 Biology 22, 363-372.

424 Andersen MB, Pingel J, Kjær M, Langberg H., 2011. Interleukin-6: a growth factor stimulating 425 collagen synthesis in human tendon. Journal of Applied Physiology 110: 1549-1554.

426 Ando, W., Tateishi, K., Hart, D.A., Katakai, D., Tanaka, Y., Nakata, K., Hashimoto, J., Fujie, H.,

427 Shino, K., Yoshikawa, H., Nakamura, N., 2007. Cartilage repair using an in vitro generated

428 scaffold-free tissue-engineered construct derived from porcine synovial mesenchymal stem cells.

429 Biomaterials 28, 5462-5470.

430 Ando, W., Tateishi, K., Katakai, D., Hart, D.A., Higuchi, C., Nakata, K., Hashimoto, J., Fujie,

431 H., Shino, K., Yoshikawa, H., Nakamura, N., 2008. In vitro generation of a scaffold-free tissue-

432 engineered construct (TEC) derived from human synovial mesenchymal stem cells: biological

433 and mechanical properties and further chondrogenic potential. Tissue Engineering Part A 14, 434 2041-2049. 
435 Asparuhova, M.B., Gelman, L., Chiquet, M., 2009. Role of the actin cytoskeleton in tuning

436 cellular responses to external mechanical stress. Scandanavian Journal of Medicine and Science

437 in Sports 19, 490-499.

438 Benito, M.J., Veale, D.J., FitzGerald, O., van den Berg, W.B., Bresnihan, B., 2005. Synovial

439 tissue inflammation in early and late osteoarthritis. Annals of Rheumatic Diseases 64, 1263-1267.

440 Berjon, J.J., Munuera, L., Calvo, M., 1991. Degenerative lesions in the articular cartilage after

441 meniscectomy: preliminary experimental study in dogs. Journal of Trauma 31, 342-350.

442 Bleedorn, J.A., Greuel, E.N., Manley, P.A., Schaefer, S.L., Markel, M.D., Holzman, G., Muir, P., 443 2011. Synovitis in dogs with stable stifle joints and incipient cranial cruciate ligament rupture: a 444 cross-sectional study. Veterinary Surgery 40, 531-543.

445 Buckwalter, J.E.T.S.S., 2000. Orthopaedic Basic Science: Biology and Biomechanics of the 446 Musculoskeletal System, 2nd ed., American Academy of Orthopaedic Surgeons, Rosemont, IL, 447 USA.

448 Chan, D.D., Van Dyke, W.S., Bahls, M., Connell, S.D., Critser, P., Kelleher, J.E., Kramer, M.A., 449 Pearce, S.M., Sharma, S., Neu, C.P., 2011. Mechanostasis in apoptosis and medicine. Progress in 450 Biophysics and Molecular Biology 106, 517-524.

451 Connor, J.R., LePage, C., Swift, B.A., Yamashita, D., Bendele, A.M., Maul, D., Kumar, S., 2009.

452 Protective effects of a cathepsin K inhibitor, SB-553484, in the canine partial medial

453 meniscectomy model of osteoarthritis. Osteoarthritis and Cartilage 17, 1236-1243. 
454 Cox, J.S., Nye, C.E., Schaefer, W.W., Woodstein, I.J., 1975. The degenerative effects of partial 455 and total resection of the medial meniscus in dogs' knees. Clinical Orthopaedics and Related 456 Research, 178-183.

457 Daireaux, M., Redini, F., Loyau, G., Pujol, J.P., 1990. Effects of associated cytokines (IL-1, TNF458 alpha, IFN-gamma and TGF-beta) on collagen and glycosaminoglycan production by cultured 459 human synovial cells. International Journal of Tissue Reactions 12, 21-31.

460 Fiorito, S., Magrini, L., Adrey, J., Mailhe, D., Brouty-Boye, D., 2005. Inflammatory status and 461 cartilage regenerative potential of synovial fibroblasts from patients with osteoarthritis and 462 chondropathy. Rheumatology (Oxford) 44, 164-171.

463 Gardner, K., Lavagnino, M., Egerbacher, M., Arnoczky, S.P., 2012. Re-establishment of 464 cytoskeletal tensional homeostasis in lax tendons occurs through an actin-mediated cellular 465 contraction of the extracellular matrix. Journal of Orthopedic Research 30, 1695-1701.

466 Goddard, D.H., Grossman, S.L., Moore, M.E., 1990. Autocrine regulation of rheumatoid arthritis 467 synovial cell growth in vitro. Cytokine 2, 149-155.

468 Grimmer, C., Balbus, N., Lang, U., Aigner, T., Cramer, T., Muller, L., Swoboda, B., Pfander, D., 469 2006. Regulation of type II collagen synthesis during osteoarthritis by prolyl-4-hydroxylases:

470 possible influence of low oxygen levels. American Journal of Pathology 169, 491-502. 
471 Hamlet, W., Liu, S.H., Yang, R., 1997. Destruction of a cyropreserved meniscal allograft: a case

472 for acute rejection. Arthroscopy 13, 517-521.

473 Ignat'eva, N.Y., Danilov, N.A., Averkiev, S.V., Obrezkova, M.V., Lunin, V.V., Sobol, E.N.,

474 2007. Determination of hydroxyproline in tissues and the evaluation of the collagen content of

475 the tissues. Journal of Analytical Chemistry 62, 51-57.

476 Kambic, H.E., Futani, H., McDevitt, C.A., 2000. Cell, matrix changes and alpha-smooth muscle

477 actin expression in repair of the canine meniscus. Wound Repair and Regeneration 8, 554-561.

478 Krawetz, R.J., Wu, Y.E., Martin, L., Rattner, J.B., Matyas, J.R., Hart, D.A., 2012. Synovial fluid

479 progenitors expressing CD90+ from normal but not osteoarthritic joints undergo chondrogenic

480 differentiation without micro-mass culture. PLoS One 7, e43616.

481 Krey, P.R., Scheinberg, M.A., Cohen, A.S., 1976. Fine structural analysis of rabbit synovial cells.

482 II. Fine structure and rosette-forming cells of explant and monolayer cultures. Arthritis and

483 Rheumatism 19, 581-592.

484 Leask, A., Abraham, D.J., 2004. TGF-beta signaling and the fibrotic response. The FASEB 485 Journal 18, 816-827.

486 Lindroos, B., Aho, K.L., Kuokkanen, H., Raty, S., Huhtala, H., Lemponen, R., Yli-Harja, O.,

487 Suuronen, R., Miettinen, S., 2010. Differential gene expression in adipose stem cells cultured in 488 allogeneic human serum versus fetal bovine serum. Tissue Engineering Part A 16, 2281-2294. 
489 Martelli-Junior H., Cotrim P., Graner E., Sauk J.J., Coletta R.D., 2003. Effect of transforming 490 growth factor-beta1, interleukin-6, and interferon-gamma on the expression of type I collagen, 491 heat shock protein 47, matrix metalloproteinase (MMP)-1 and MMP-2 by fibroblasts from 492 normal gingiva and hereditary gingival fibromatosis. The Journal of Periodontology 74, $296-306$.

493 McDevitt, C.A., Webber, R.J., 1990. The ultrastructure and biochemistry of meniscal cartilage. 494 Clinical Orthopaedics and Related Research 252, 8-18.

495 Miyamoto, C., Matsumoto, T., Sakimura, K., Shindo, H., 2007. Osteogenic protein-1 with 496 transforming growth factor-beta1: potent inducer of chondrogenesis of synovial mesenchymal 497 stem cells in vitro. Journal of Orthopedic Science 12, 555-561.

498 Mussener, A., Funa, K., Kleinau, S., Klareskog, L., 1997. Dynamic expression of transforming 499 growth factor-betas (TGF-beta) and their type I and type II receptors in the synovial tissue of 500 arthritic rats. Clinical and Experimental Immunology 107, 112-119.

501 Ochi, M., Ishida, O., Daisaku, H., Ikuta, Y., Akiyama, M., 1995. Immune response to fresh 502 meniscal allografts in mice. Journal of Surgical Research 58, 478-484.

503 Oehler, S., Neureiter, D., Meyer-Scholten, C., Aigner, T., 2002. Subtyping of osteoarthritic 504 synoviopathy. Clinical and Experimental Rheumatology 20, 633-640.

505 Okada, Y., Naka, K., Minamoto, T., Ueda, Y., Oda, Y., Nakanishi, I., Timpl, R., 1990. localization 506 of type VI collagen in the lining cell layer of normal and rheumatoid synovium. Laboratory 507 Investigation 63, 647-656. 
508 Pangborn, C.A., Athanasiou, K.A., 2005a. Effects of growth factors on meniscal 509 fibrochondrocytes. Tissue Engineering 11, 1141-1148.

510 Pangborn, C.A., Athanasiou, K.A., 2005b. Growth factors and fibrochondrocytes in scaffolds. 511 Journal of Orthopedic Research 23, 1184-1190.

512 Pei, M., He, F., Kish, V.L., Vunjak-Novakovic, G., 2008a. Engineering of functional cartilage 513 tissue using stem cells from synovial lining: a preliminary study. Clinical Orthopedics and 514 Related Research 466, 1880-1889.

515 Pei, M., He, F., Vunjak-Novakovic, G., 2008b. Synovium-derived stem cell-based 516 chondrogenesis. Differentiation 76, 1044-1056.

517 Pessina, A., Bonomi, A., Baglio, C., Cavicchini, L., Sisto, F., Neri, M.G., Gribaldo, L., 2008.

518 Microbiological risk assessment in stem cell manipulation. Critical Review of Microbiology 34, $519 \quad 1-12$.

520 Price, F.M., Levick, J.R., Mason, R.M., 1996. Glycosaminoglycan concentration in synovium and 521 other tissues of rabbit knee in relation to synovial hydraulic resistance. Journal of Physiology 495 522 (Pt 3), 803-820.

523 Rodeo, S.A., Seneviratne, A., Suzuki, K., Felker, K., Wickiewicz, T.L., Warren, R.F., 2000.

524 Histological analysis of human meniscal allografts. A preliminary report. Journal of Bone and 525 Joint Surgery of America 82-A, 1071-1082. 
526 Smith, M.D., Triantafillou, S., Parker, A., Youssef, P.P., Coleman, M., 1997. Synovial membrane

527 inflammation and cytokine production in patients with early osteoarthritis. Journal of

528 Rheumatology 24, 365-371.

529 Smith, T.J., Baltzer, W.I., Lohr, C., Stieger-Vanegas, S.M., 2012. Primary synovial

530 osteochondromatosis of the stifle in an English Mastiff. Veterinary Comparative Orthopaedics

531 and Traumatology 25, 160-166.

532 Stephan, J.S., McLaughlin, R.M., Jr., Griffith, G., 1998. Water content and glycosaminoglycan

533 disaccharide concentration of the canine meniscus. American Journal of Veterinary Research 59, $534 \quad 213-216$.

535 Strober, W., 2001. Trypan blue exclusion test of cell viability. Current Protocols of Immunology 536 Appendix 3B.

537 Sutton, S., Clutterbuck, A., Harris, P., Gent, T., Freeman, S., Foster, N., Barrett-Jolley, R.,

538 Mobasheri, A., 2007. The contribution of the synovium, synovial derived inflammatory cytokines

539 and neuropeptides to the pathogenesis of osteoarthritis. The Veterinary Journal.

540 Tienen, T.G., Heijkants, R.G., de Groot, J.H., Schouten, A.J., Pennings, A.J., Veth, R.P., Buma, P.,

541 2006. Meniscal replacement in dogs. Tissue regeneration in two different materials with similar

542 properties. Journal of Biomedical Materials Research Part B: Applied Biomaterials 76, 389-396. 
543 Vickers, S.M., Johnson, L.L., Zou, L.Q., Yannas, I.V., Gibson, L.J., Spector, M., 2004.

544 Expression of alpha-smooth muscle actin by and contraction of cells derived from synovium.

545 Tissue Engineering 10, 1214-1223.

546 Warnock, J.J., Baltzer, W.I., Duesterdieck-Zellmer, K., Ott, J., 2012. Minimally invasive

547 synovium harvest for potential use in meniscal tissue engineering. Research in Veterinary Science $54893,1472-1480$.

549 Warnock, J.J., Duesterdieck-Zellmer, K.F., Bobe, G., Baltzer, W.I., Ott, J., 2013. Synoviocyte 550 neotissues towards in vitro meniscal tissue engineering. Research in Veterinary Science.

551 Warnock, J.J., Fox, D.B., Stoker, A.M., Cook, J.L., 2011. Evaluation of in vitro growth factor 552 treatments on fibrochondrogenesis by synovial membrane cells from osteoarthritic and 553 nonosteoarthritic joints of dogs. American Journal of Veterinary Research 72, 500-511.

554 Wei, H., Shen, G., Deng, X., Lou, D., Sun, B., Wu, H., Long, L., Ding, T., Zhao, J., 2013. The 555 role of IL-6 in bone marrow (BM)-derived mesenchymal stem cells (MSCs) proliferation and 556 chondrogenesis. Cell Tissue Bank DOI:10.1007/s10561-012-9354-9.

557 Xu, T., Wu, M., Feng, J., Lin, X., Gu, Z., 2012. RhoA/Rho kinase signaling regulates 558 transforming growth factor-betal-induced chondrogenesis and actin organization of synovium559 derived mesenchymal stem cells through interaction with the Smad pathway. International 560 Journal of Molecular Medicine 30, 1119-1125. 
561 Zhang, N., Dietrich, M.A., Lopez, M.J., 2013. Canine intra-articular multipotent stromal cells

562 (MSC) from adipose tissue have the highest in vitro expansion rates, multipotentiality, and MSC

563 immunophenotypes. Veterinary Surgery 42, 137-146. 


\section{Figure 1}

Hyperconfluent cell sheets.

Representative example of a hyperconfluent cell sheet just prior to harvest for formation of a tensioned synoviocyte bioscaffold. A) gross appearance of the hyperconfluent cell sheet in monolayer culture, and B) phase contrast photomicrograph of the hyperconfluent cell sheet, 10X objective magnification, bar $=100 \mu \mathrm{m}$.
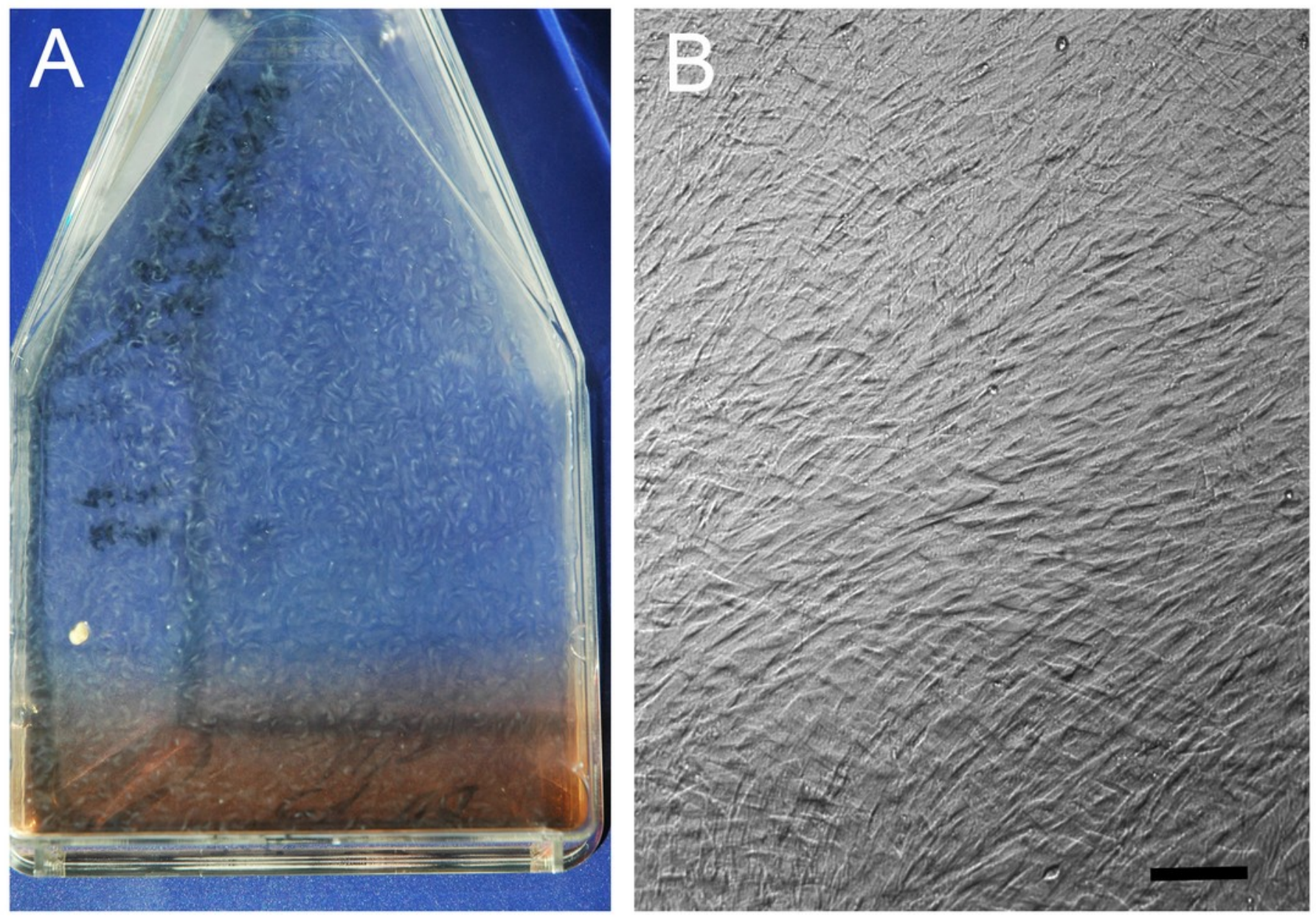


\section{Figure 2}

Tensioned synoviocyte bioscaffolds.

Representative samples of a tensioned synoviocyte bioscaffold synthesized from normal joint origin synoviocytes, or nTSB ("N"), and a tensioned synoviocyte bioscaffold from osteoarthritic joint origin

synoviocytes, or "oaTSB," (“OA").
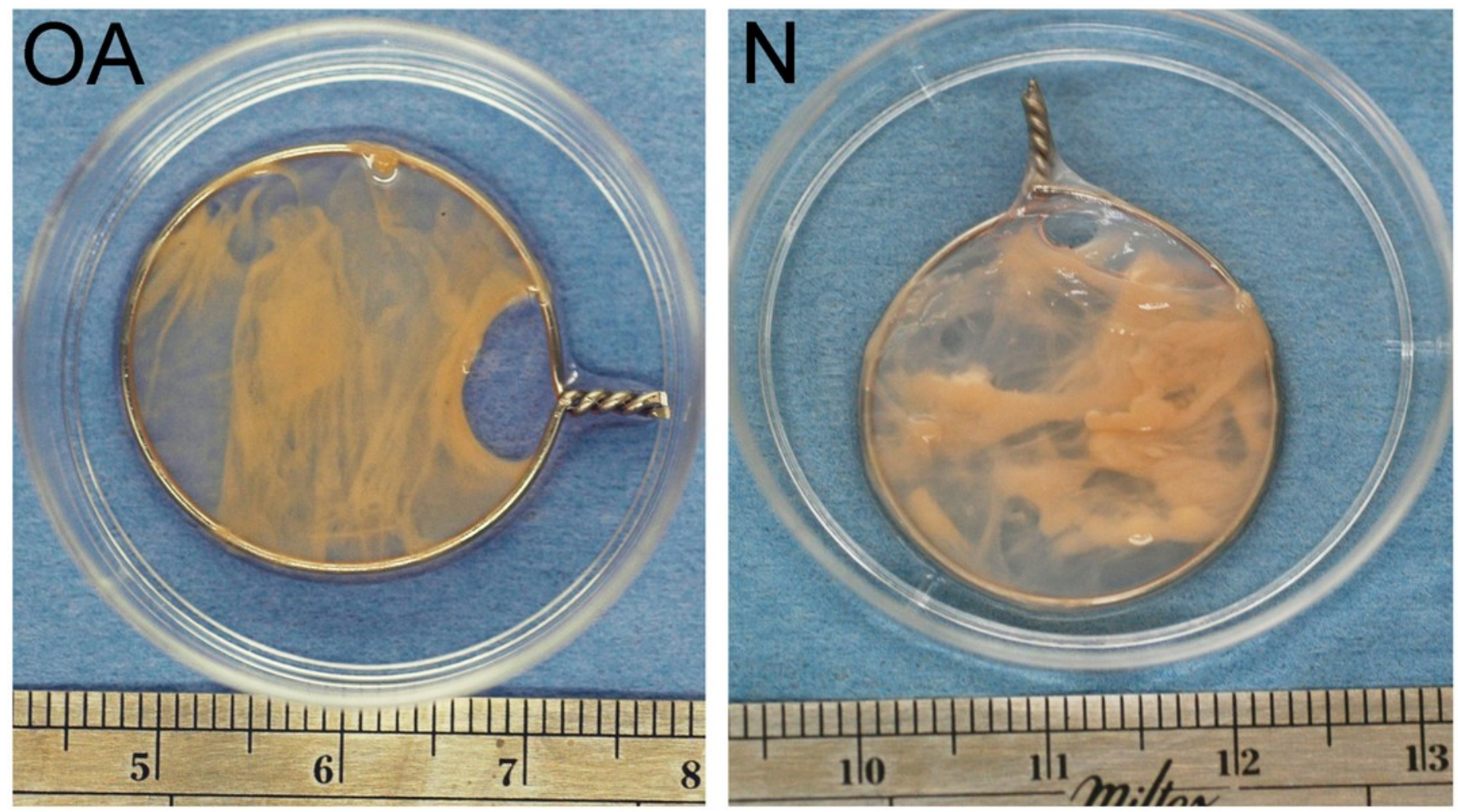


\section{Figure 3}

Bioscaffold cellularity and alpha- smooth muscle actin.

Hematoxylin and Eosin stain of normal joint-origin synoviocyte bioscaffolds ("N H\&E ") and osteoarthritic joint-origin synoviocyte bioscaffolds ("OA H\&E "). Immunohistochemisty for alpha smooth muscle actin (ASM) of normal joint-origin synoviocyte bioscaffolds ("N ASM ") and osteoarthritic joint-origin synoviocyte bioscaffolds ("OA ASM "). Note the more extensive expression of ASM in the osteoarthritic joint-origin synoviocyte bioscaffold cells, and regional strong ASM expression along the periphery of spontaneously forming defects $\left({ }^{*}\right)$ in the normal and osteoarthritic joint-origin bioscaffolds. Immunohistochemistry negative controls of normal joint-origin synoviocyte bioscaffolds ("N NC ") and osteoarthriticjoint-origin synoviocyte bioscaffolds ("OA NC "). 10X objective magnification, bar $=100 \mu \mathrm{m}$. 

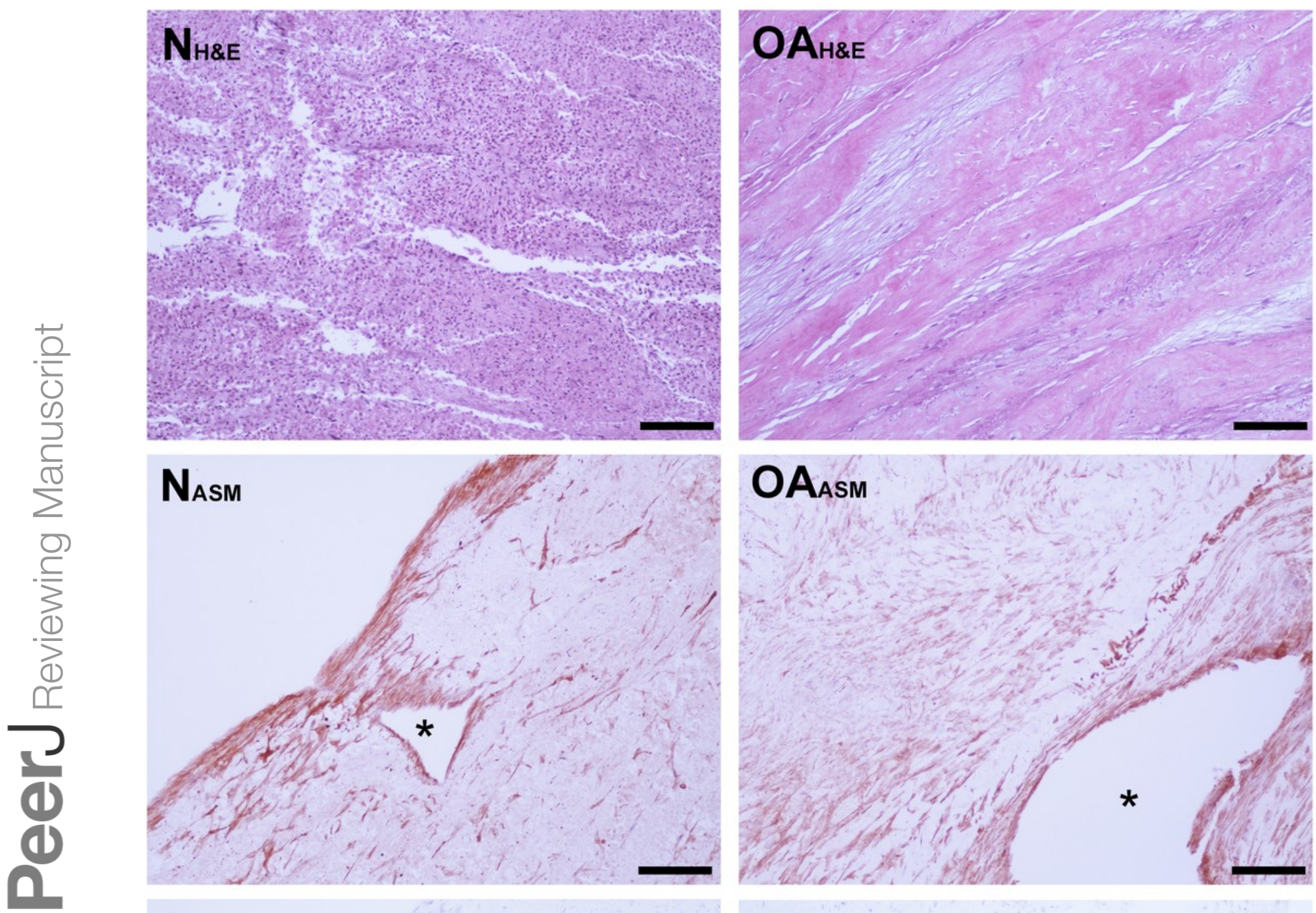

\section{$\mathbf{N}_{\mathrm{NC}}$}

\section{$\mathrm{OA}_{\mathrm{NC}}$}




\section{Figure 4}

Histology scores for tensioned synoviocyte bioscaffolds

Histology scores for type I collagen, typell collagen, glycosaminoglycan, and alpha-smooth muscle actin in normaljoint-origin tensioned synoviocyte bioscaffolds versus osteoarthritic joint-origin tensioned synoviocyte bioscaffolds, showing the median and interquartile range. Histologic scores for collagens type 1 and 2 were calculated as follows: Histologic score= [[( \% positive staining cells $\mathrm{x}$ intracellular staining intensity $)+(\%$ positive stained extracellular area $x$ extracellular staining intensity)]/2]. The histologic score for alpha smooth muscle actin (ASMA) was calculated by ( $\%$ positive staining cells $x$ intracellular staining intensity). The histologic score for glycosaminoglycan (GAG) was calculated by (\% positive stained extracellular area $x$ extracellular staining intensity). An $\left(^{*}\right)$ denotes statistical significance. [p] 


\section{Bioscaffold Histologic Scores}

$\alpha$ Smooth Muscle Actin

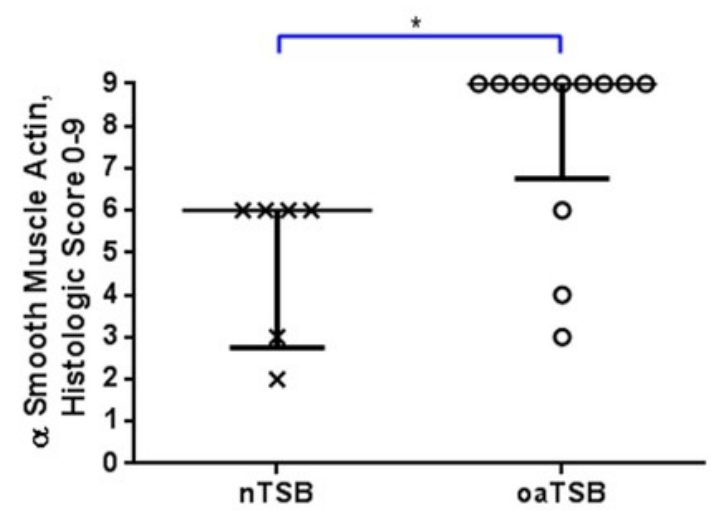

Collagen Type 1

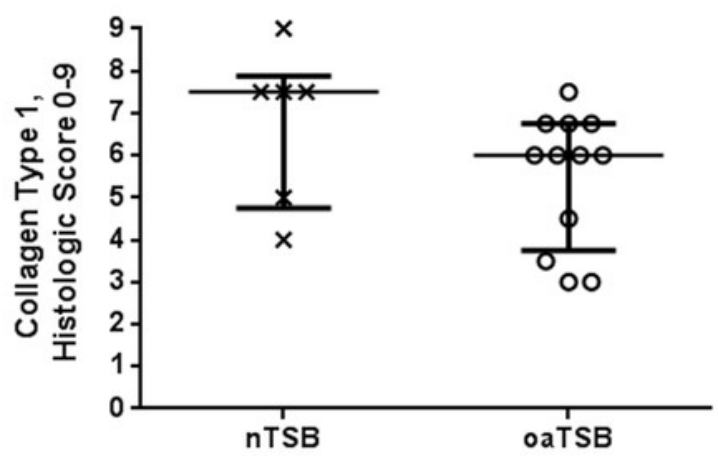

Glycosaminoglycan

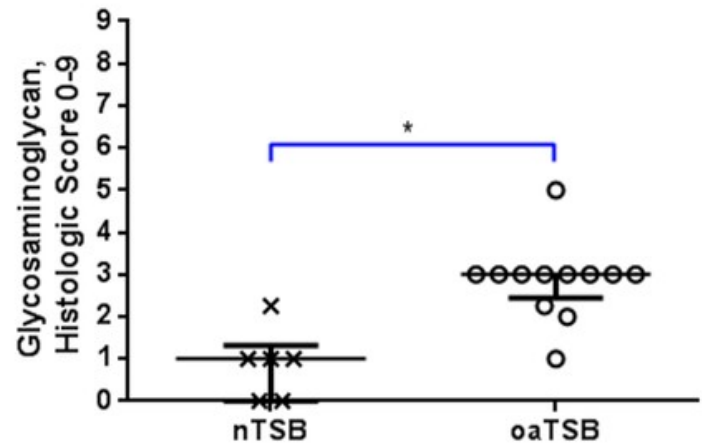

Collagen Type 2

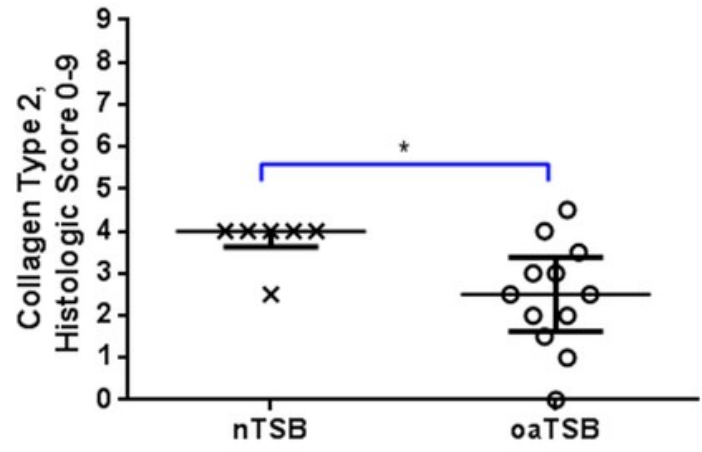




\section{Figure 5}

Histologic analysis of glycosaminoglycan content of tensioned synoviocyte bioscaffolds.

Histologic analysis of glycosaminoglycan content of tensioned synoviocyte bioscaffolds

Toluidine Blue staining for glycosaminoglycan of normaljoint-origin tensioned synoviocyte bioscaffolds ("NTB") and osteoarthriticjoint- origin tensioned synoviocyte bioscaffolds ("OATB"). 10Xobjective magnification, bar $=100 \mu \mathrm{m}$.
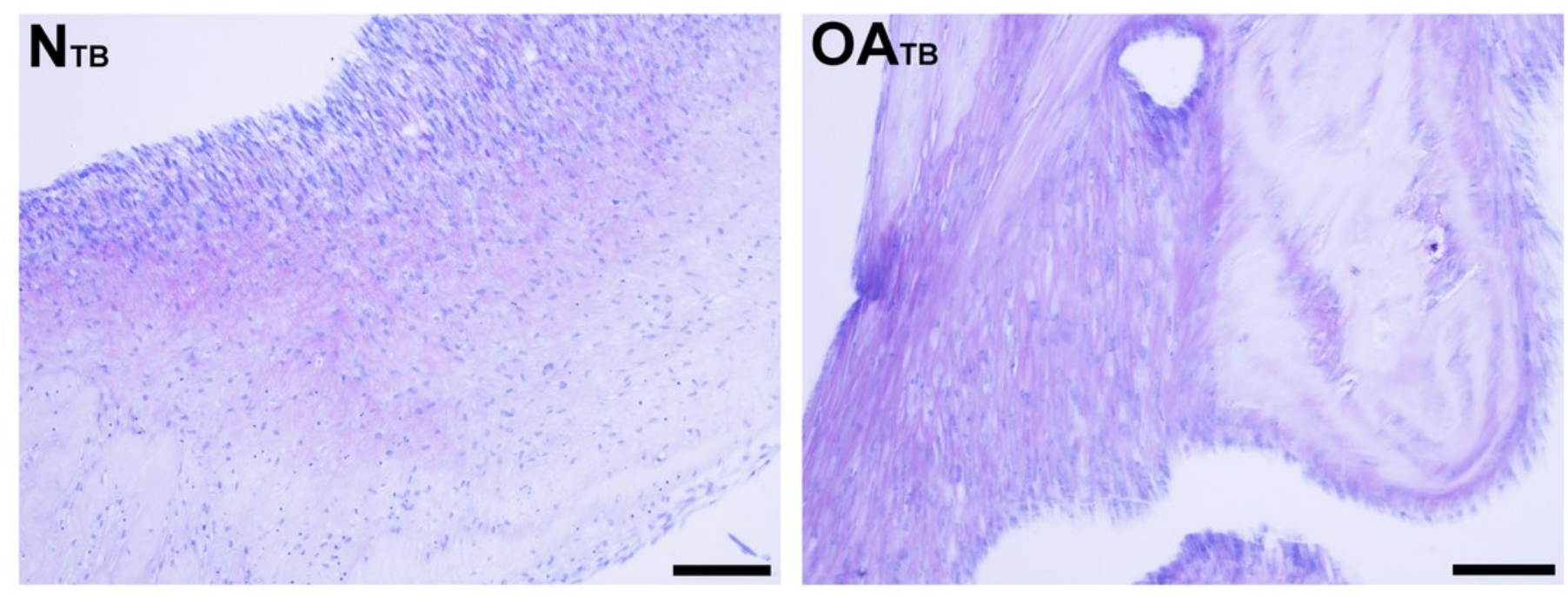


\section{Figure 6}

Histologic analysis of collagen content of tensioned synoviocyte bioscaffolds.

Masson's Trichrome staining for collagen of normal joint-origin synoviocyte bioscaffolds ("NMT") and osteoarthritic joint-origin synoviocyte bioscaffolds ("OA MT").

Immunohistochemistry for type I collagen and type II collagen of normal joint-origin synoviocyte bioscaffolds ("NCOL1" and "NCOL2") and osteoarthritic joint-origin synoviocyte bioscaffolds ("OACOL1" and "OACOL2"). In this example the type I collagen ECM of both bisocaffolds is moderately positive. For type II collagen, the cells are moderately immunoreactive and the ECM is mildly immunoreactive in the normal joint-origin synoviocyte bioscaffold, while the cells and ECM of the osteoarthritic joint-origin bioscaffold are mildly immunoreactive. 10X objective.

magnification, bar $=100 \mu \mathrm{m}$.

$[\mathrm{p}]$ 

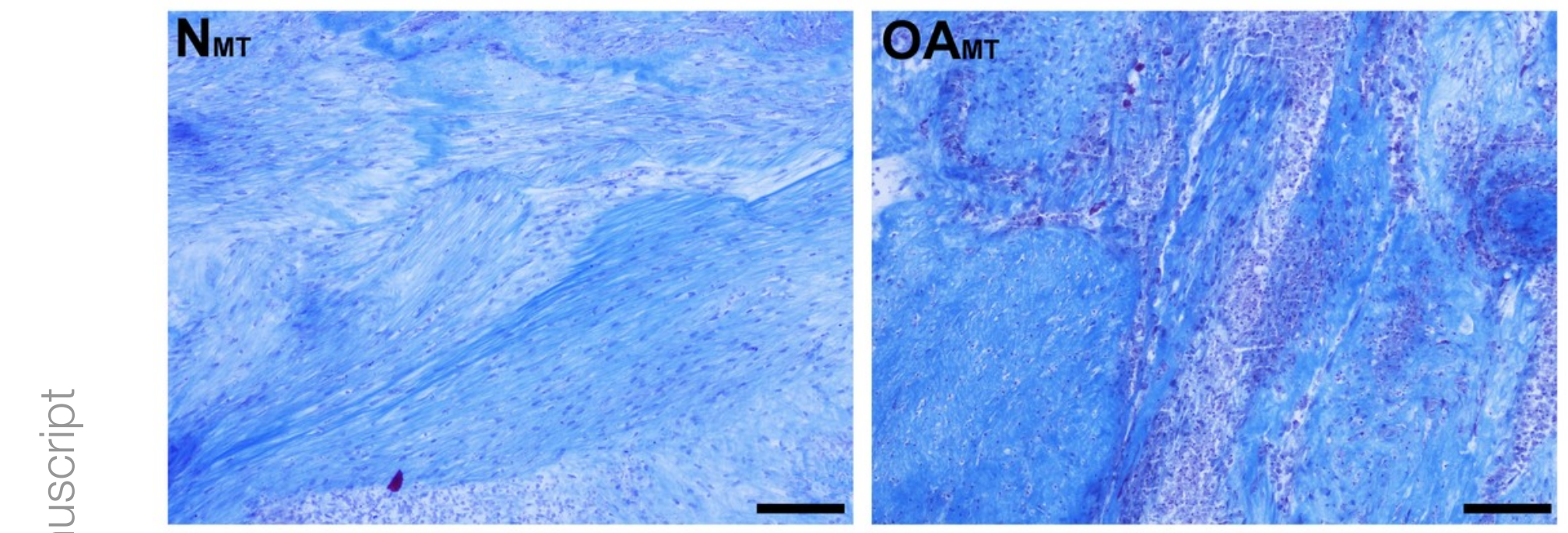

\section{Ncol1}

OAcol1

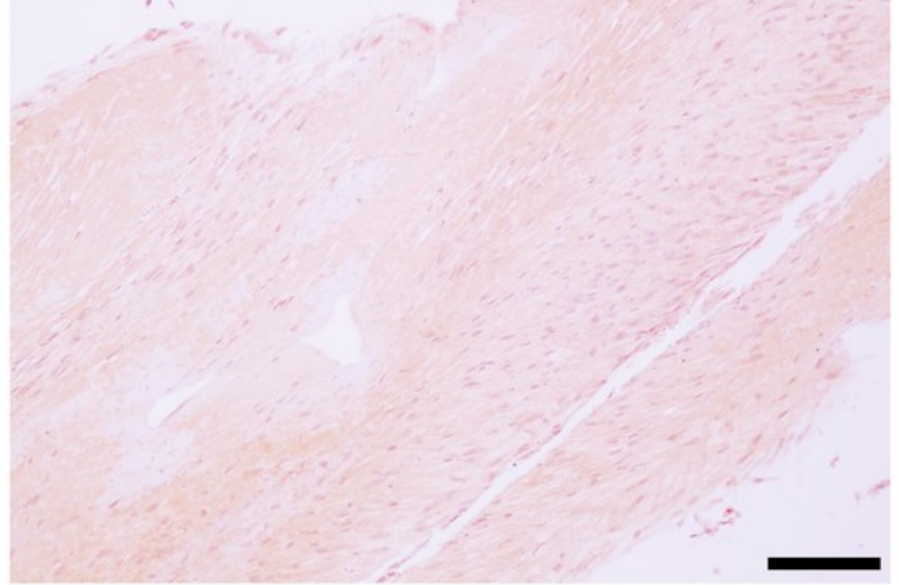

\section{$\mathbf{N}_{\text {col2 }}$}

OAcol2
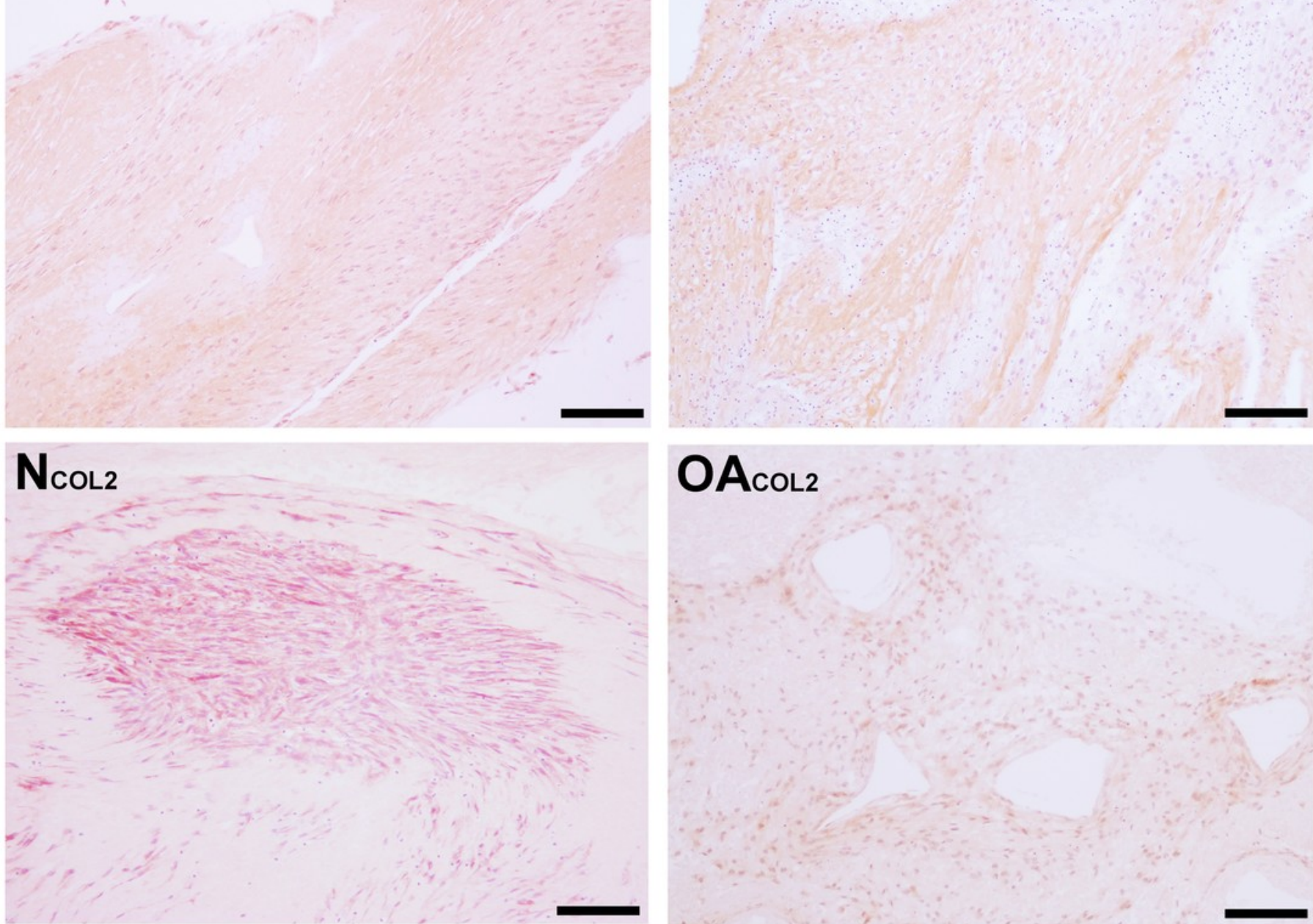

\section{A A}




\section{Figure 7}

Immunohistochemical analysis for macrophages

Immunohistochemistry for the macrophage MAC387 receptor, to determine type A synoviocyte content, in a lymph node (positive control, "PC ${ }_{\text {MAC }}$ "), normal joint- origin bioscaffold ("N $\mathrm{NAC}_{\text {") and osteoarthritic joint-origin synoviocyte bioscaffolds ("OA }}$ MAC").

Negative controls are as pictured in Fig.3. Note the lack of immunoreactivity in the bioscaffold samples. The positive control, a canine lymph node, is shown at $20 \mathrm{X}$ objective magnification, bar $=100 \mu \mathrm{m}$, to allow clearer viewing of the macrophages. To show adequate representation of the bioscaffold neotissues, $\mathrm{N}_{\text {MAC }}$ and $\mathrm{OA}{ }_{\text {MAC }}$ are pictured at $10 \mathrm{X}$ objective magnification, bar $=100 \mu \mathrm{m}$. 


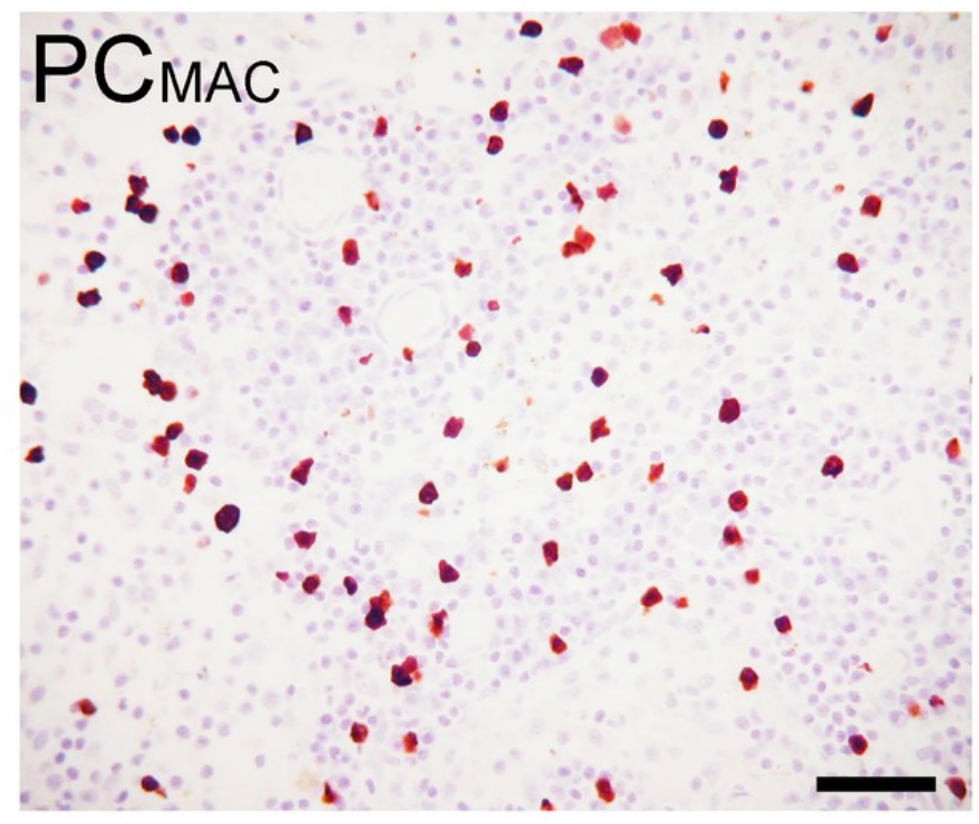

NMAC

OAmAC 


\section{Table $\mathbf{1}_{\text {(on next page) }}$}

Histologic scoring system

Extracellular and intracellular immunoreactivity intensity was localized to intracellular or extracellular staining, and ECM immunoreactivity intensity was described and scored as negative (0), mild (1), moderate (2), or strong (3) staining. As determined by hand count, intracellular immunoreactivity and extracellular immunoreactivity was categorized as positive in $\langle 10 \%, 10-50 \%$, or $>50 \%$ of cells and sample area, respectively. Each of these histologic observations was assigned a score (Table 2). Then a histologic intensity coefficient was calculated for each ECM component, as follows: [[(Extracellular matrix staining intensity score) $\times$ (percentage area coverage of positive staining score) $]+[($ Intracellular staining intensity score) $\mathrm{x}$ (percentage positive staining cells score)]]/2 (Table 1). 
Table 1.

Histologic scoring system:

\begin{tabular}{|l|l|l|l|l|l|l|l|l|}
\hline \multirow{2}{*}{} & \multicolumn{3}{|l|}{$\%$ Positive staining cells } & \multicolumn{3}{l|}{ Intracellular staining intensity } \\
\cline { 2 - 9 } & None & $<10 \%$ & $10-50 \%$ & $>50 \%$ & None & Mild & Moderate & Strong \\
\hline $\begin{array}{l}\text { Intracellular } \\
\text { score }\end{array}$ & 0 & 1 & 2 & 3 & 0 & 1 & 2 & 3 \\
\hline & $\%$ Positive stained extracellular area & \multicolumn{2}{|l|}{ Extracellular staining intensity } \\
\cline { 2 - 9 } & None & $<10 \%$ & $10-50 \%$ & $>50 \%$ & None & Mild & Moderate & Strong \\
\hline $\begin{array}{l}\text { Extracellula } \\
\text { r score }\end{array}$ & 0 & 1 & 2 & 3 & 0 & 1 & 2 & 3 \\
\hline
\end{tabular}




\section{Table 2 (on next page)}

Gene expression in tensioned synoviocyte bioscaffolds

The effect of osteoarthritis on fibrochondrogenic gene expression of tensioned synoviocyte bioscaffolds (fold-changes \pm SEM). Fold changes were calculated using the following formula: fold change $=2^{-\triangle \triangle C T}=\left[\left(C_{T}\right.\right.$ gene of interest $-C_{T}$ housekeeping gene GAPDH $)$ oaTSB $^{-}\left(C_{T}\right.$ geneof interest $-\mathrm{C}_{\mathrm{T}}$ housekeeping gene GAPDH) ${ }_{\mathrm{nTSB}}$ ]. 
Table 2: The effect of osteroarthritis on fibrochondrogenic gene expression of tensioned synoviocyte bioscaffolds (fold-changes \pm SEM). Fold changes were calculated using the following formula: fold change $=2^{-\Delta \Delta C T}=\left[\left(C_{\mathrm{T}} \text { gene of interest }-\mathrm{C}_{\mathrm{T}} \text { housekeeping gene GAPDH }\right)_{\mathrm{oaTSB}}-\left(\mathrm{C}_{\mathrm{T}}\right.\right.$ gene of interest $\mathrm{C}_{\mathrm{T}}$ housekeeping gene GAPDH) $\left.)_{\mathrm{nTSB}}\right]$.

\begin{tabular}{lllll}
\hline & \multicolumn{3}{c}{ Tensioned Synoviocyte Bioscaffolds (TSB) } & \\
\cline { 2 - 5 } Dog & Normal & Osteoarthritis & SEM & P-value \\
\hline Gene: & $\mathrm{N}=4$ & $\mathrm{~N}=7$ & & \\
SOX-9 & $0^{\text {Reference }}$ & +1.17 & 1.54 & 0.72 \\
& & & & \\
Collagen type I $\alpha 1$ & 0 & +6.88 & 2.62 & 0.04 \\
Collagen type II $\alpha 1$ & 0 & +71.1 & 4.48 & 0.02 \\
Aggrecan & 0 & -1.15 & 1.77 & 0.84 \\
Interleukin-6 & 0 & -19.0 & 2.01 & 0.001 \\
Tumor Necrosis Factor $\alpha$ & 0 & +1.49 & 2.55 & 0.77 \\
\hline
\end{tabular}




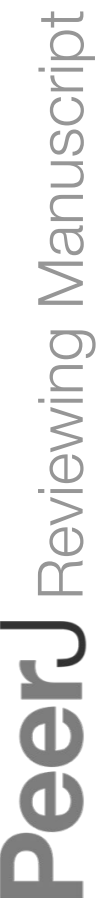

PeerJ reviewing PDF | (v2014:06:2238:2:1:NEW 26 Aug 2014) 


\section{Table 3 (on next page)}

Extracellular matrix and dsDNA content of tensioned synoviocyte bioscaffolds

The effect of osteoarthritis on extracellular matrix and double stranded- DNA composition of tensioned synoviocyte bioscaffolds. Data is reported as mean \pm SEM. 
Table 3: The effect of osteroarthritis on extracellular matrix composition of tensioned synoviocyte bioscaffolds. Data is reported as mean \pm SEM.

\begin{tabular}{llll}
\hline & \multicolumn{2}{c}{ Tensioned Synoviocyte Bioscaffolds (TSB) } & \\
\cline { 2 - 3 } Dog: & Normal & Osteoarthritis & P-Value \\
\hline & $\mathrm{N}=6$ & $\mathrm{~N}=12$ & \\
Concentrations $(\mu \mathrm{g} /$ /neotissue): & & & 0.02 \\
Glycosaminoglycan & $684 \pm 74$ & $434 \pm 44$ & 0.29 \\
Collagen & $4855 \pm 1270$ & $3302 \pm 392$ & 0.71 \\
DNA & $47.4 \pm 11.9$ & $42.3 \pm 5.2$ & \\
& & & 0.11 \\
Proportion (\% dry weight): & $1.73 \pm 0.11$ & $2.05 \pm 0.16$ & 0.20 \\
Glycosaminoglycan & $12.1 \pm 2.4$ & $16.6 \pm 2.4$ & 0.01 \\
Collagen & $0.111 \pm 0.020$ & $0.214 \pm 0.030$ & \\
DNA & & & 0.13 \\
& & & 0.35 \\
\hline Index ( $\mu$ g/ug dsDNA): & $18.7 \pm 3.9$ & $11.4 \pm 1.6$ & \\
GAG & $132 \pm 36$ & $92.0 \pm 17.5$ & \\
Collagen & & & \\
\hline
\end{tabular}

